\title{
Elevated expression of IFN-inducible CXCR3 ligands predicts poor prognosis in patients with non-metastatic clear-cell renal cell carcinoma
}

\author{
Weisi Liu' ${ }^{1}$, Yidong Liu ${ }^{1}$, Qiang Fu' ${ }^{1}$, Lin Zhou ${ }^{2}$, Yuan Chang ${ }^{2}$, Le $X u^{3}$, Weijuan Zhang ${ }^{4}$, \\ Jiejie $X \mathbf{u}^{1}$ \\ ${ }^{1}$ Department of Biochemistry and Molecular Biology, School of Basic Medical Sciences, Fudan University, Shanghai, China \\ ${ }^{2}$ Department of Urology, Zhongshan Hospital, Fudan University, Shanghai, China \\ ${ }^{3}$ Department of Urology, Ruijin Hospital, School of Medicine, Shanghai Jiaotong University, Shanghai, China \\ ${ }^{4}$ Department of Immunology, School of Basic Medical Sciences, Fudan University, Shanghai, China \\ Correspondence to: Weijuan Zhang, e-mail: weijuanzhang@fudan.edu.cn \\ Jiejie Xu, e-mail: jjxufdu@fudan.edu.cn
}

Keywords: clear-cell renal carcinoma, CXCL9, CXCL10, CXCL11, prognostic factor

Received: October 26, 2015

Accepted: February 05, 2016

Published February 17, 2016

\section{ABSTRACT}

IFN-inducible CXCR3 ligands (ICL), namely CXCL9, CXCL10 and CXCL11, exhibit pleiotropic roles in orchestrating immunity and angiogenesis. However, the prognosis value of them in renal cell carcinoma (RCC) was still obscure. Thus, we retrospectively used immunohistochemistry approach to evaluate the impact of these ligands on recurrence and survival of non-metastatic clear cell RCC (CCRCC) patients after nephrectomy. We systemically built a prespecified ICL score based on these ligands, and found specimens with high ICL score were prone to possess high Fuhrman grade, necrosis, and high-risk level of SSIGN. Moreover, ICL score stratified patients into different risk subgroups, and remained an independent adverse prognosticator for overall survival (OS) and recurrence-free survival (RFS). Meanwhile, in TCGA database, the increasing ICL mRNA predicted poor survival and early recurrence. Furthermore, after adding ICL score into SSIGN, the C-index for OS and RFS increased from 0.705 to 0.746 and 0.712 to 0.765 , respectively. In conclusion, the ICL score based on expression of CXCL9, CXCL10 and CXCL11 stratified non-metastatic CCRCC patients into different risk subgroups of recurrence and death, which might benefit preoperative risk stratification and guide immune therapy in the future.

\section{INTRODUCTION}

Renal cell carcinoma (RCC), unlike most solid tumors, is considered an immunogenic tumor and remains one of few solid tumors that consistently respond to the currently available immunotherapies [1]. Despite the strongly infiltration of different types of immune cells, immunologic dysfunction finally promote RCC tumor growth and evasion, and contribute poor survival of patients [2-4]. Thus, recognition of immunologic dysfunction in RCC, especially clear cell renal cell carcinoma (ccRCC), the most common histological subtype of RCC, has rendered a privileged area for the development of prognostic and predictive system for stratification of patients and clinical application of precise immunotherapy.

CXC chemokine are fundamental molecules to engage different leukocyte subsets to local inflammatory sites [5]. Among them, interferon (IFN) inducible CXC chemokine, CXCL9 (Mig), CXCL10 (IP-10) and CXCL11 (I-TAC), are multifunctional chemokine orchestrating immunity and angiogenesis via shared G-protein coupled receptor CXCR3, thus, these ligands might play a crucial role in cancer $[6,7]$. Circulating levels of CXCL9 was reproducibly associated with lung cancer risk [8]. Meanwhile, in breast cancer, CXCL10/CXCR3 axis presented with tumor infiltrating lymphocytes (TILs), tumor progression and invasion, and poor prognosis 
[9, 10]. Moreover, in RCC, pervious studies found the expression of CXCL9, CXCL10 and CXCL11 increased in tumor compared to normal kidney tissues, suggesting the association with TILs and favorable prognosis, and the promotion of tumor specific immunity in systemic high-dose interleukin-2 (IL-2) therapy [11-14]. However, recently study about TILs in RCC demonstrated not only effector $\mathrm{T}$ cells but also regulatory $\mathrm{T}$ cells could be recruited via CXCR3 ligands, infiltration of Treg indicating suppression of effector $\mathrm{T}$ cells and poor prognosis of RCC patients [15-18]. Furthermore, overexpression of these ligands could enhance RCC cells metastasis $[19,20]$. Thus, IFN-inducible CXCR3 ligands might affect tumor microenvironment via a paracrine manner and play a role in tumor progression and invasion via an autocrine manner. However, the role and prognostic value of IFN-inducible CXCR3 ligands in non-metastatic ccRCC is perplexed.

Here, we used immunohistochemistry (IHC) approach to retrospectively assess the expression of CXCL9, CXCL10 and CXCL11 in non-metastatic ccRCC specimens. A prespecified score was developed based on their expression, and then correlations with clinic characteristics and outcomes and prognostic values in multivariable Cox models were analyzed.

\section{RESULTS}

\section{Association CXCL9, CXCL10 and CXCL11 expression with clinical outcomes}

CXCL9, CXCL10 and CXCL11 expression were assessed in 263 non-metastatic ccRCC specimens. We found CXCL9 and CXCL10 expressing on tumor cells and stromal cells, and CXCL11 expressing strongly on stromal cells and weakly on tumor cells (Figure 1A). According to medium value as cutoff, 122 (47.5\%), $110(42.6 \%)$ and 127 (49.4\%) were grouped as CXCL9, CXCL10 and CXCL11 high expression, respectively. Furthermore, high CXCL9 expression were positive related with Fuhrman grade and SSIGN, high CXCL10 expression were positive associated with tumor size, $\mathrm{pT}$ stage, Fuhrman grade, necrosis and the Mayo Clinic stage, size, grade and necrosis (SSIGN) score, and high CXCL11 expression were no relevant with clinic characters in our study (Supplementary Table S1).

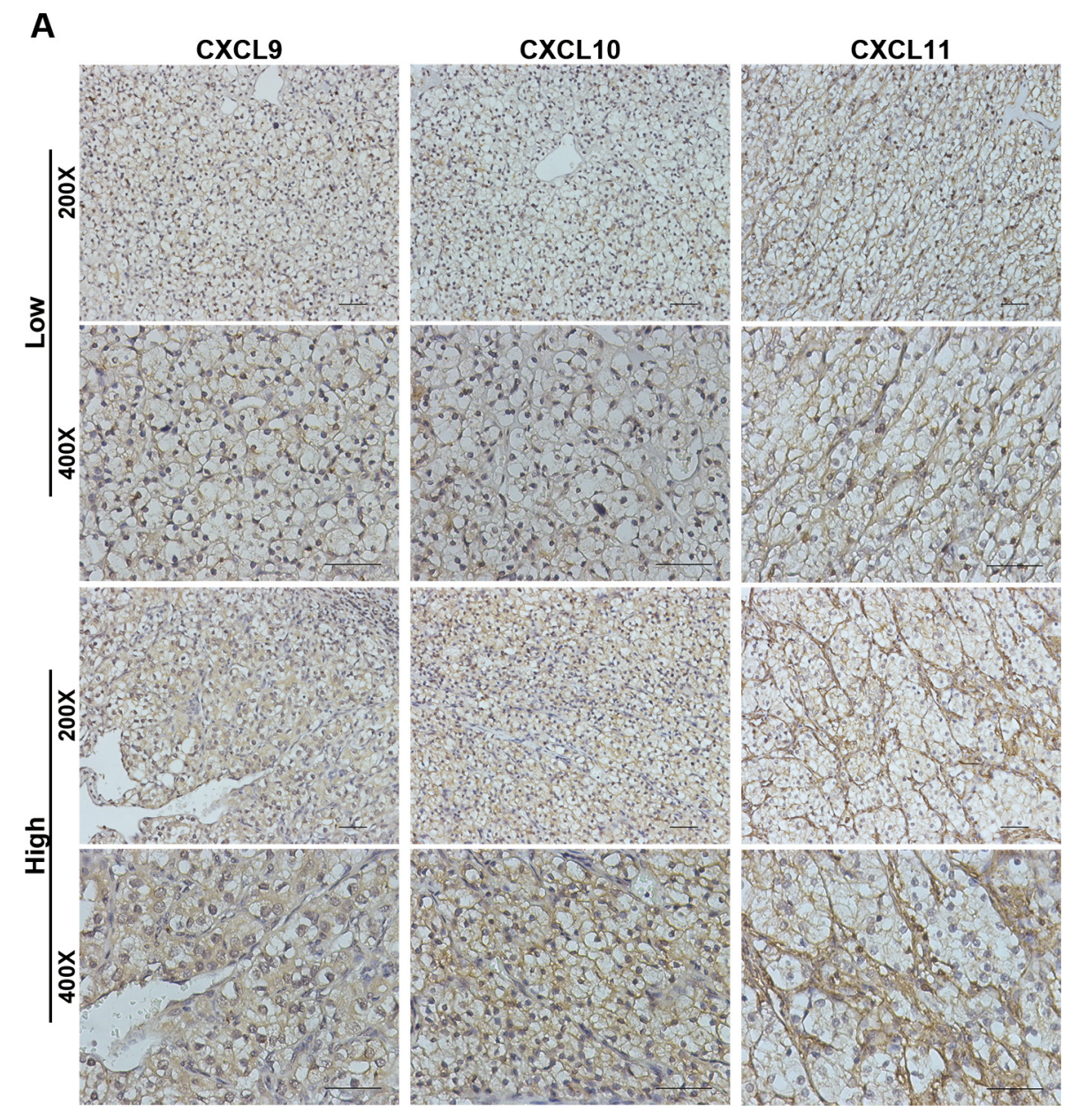

Figure 1: CXCL9, CXCL10 and CXCL11 immunohistochemical expression in non-metastatic ccRCC specimens. (A) Representative CXCL9, CXCL10 and CXCL11 immunohistochemical images in non-metastatic ccRCC specimens. Scale bar: $50 \mu \mathrm{m}$. 
At last follow-up, a mean duration of overall survival (OS) was 83.3 months (median = 98 months; range from 7-120 months) and recurrence-free survival (RFS) was 82.2 months (median $=97$ months; range from 2-120 months). The patients with high expression of CXCL9, CXCL10 and CXCL11 were more likely to have poor survival and early recurrence, respectively (Supplementary Figure S1A, S1B and S1C). Thus, we built a systemic IFN-inducible CXCR3 ligands (ICL) score to evaluate prognostic value of these ligands.

\section{Association ICL score with clinicopathologic characteristics and clinical outcomes}

In our prespecified ICL score, 77, 64, 71 and 51 specimens were stratified into four different subgroups, respectively (Figure 2A). The specimens with high ICL score tended to have high Fuhrman grade, necrosis, and high-risk level of SSIGN (Table 1). Furthermore, ICL score stratified patients into different risk subgroups of OS and RFS, where Group IV patients had the worst

A

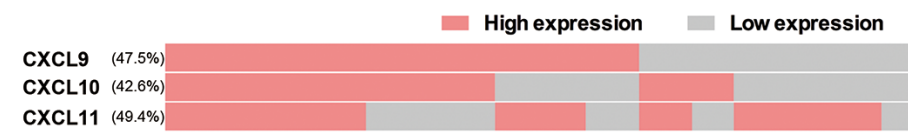

B
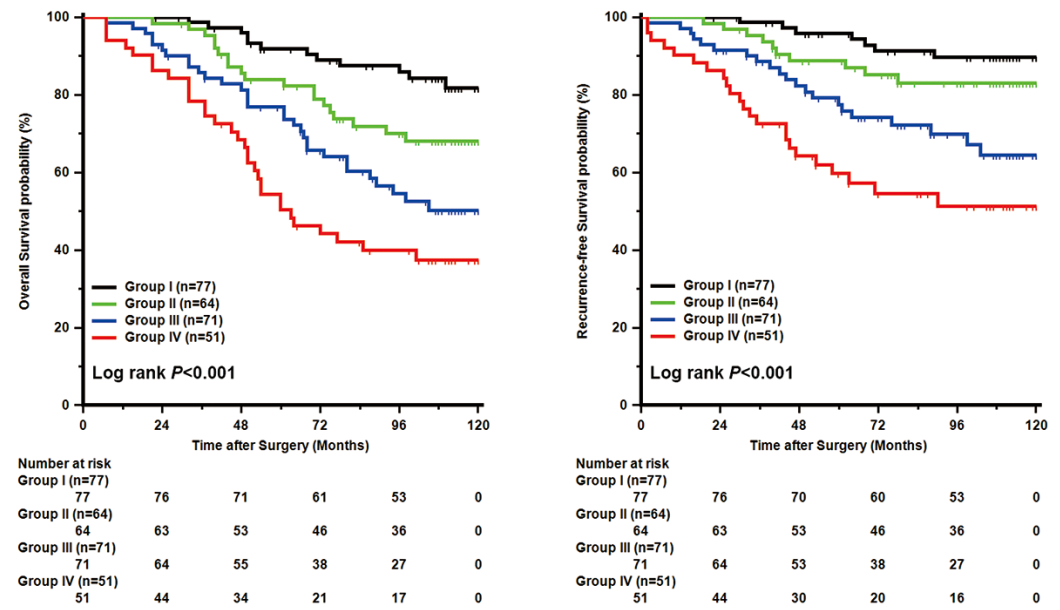

C

Altered in $74(14 \%)$ of 531 patients/cases

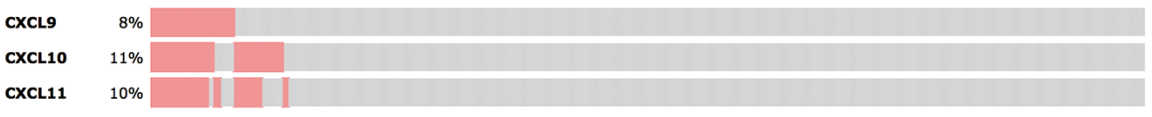

genetic alteration \mRNA Downregulation \mRNA Upregulation
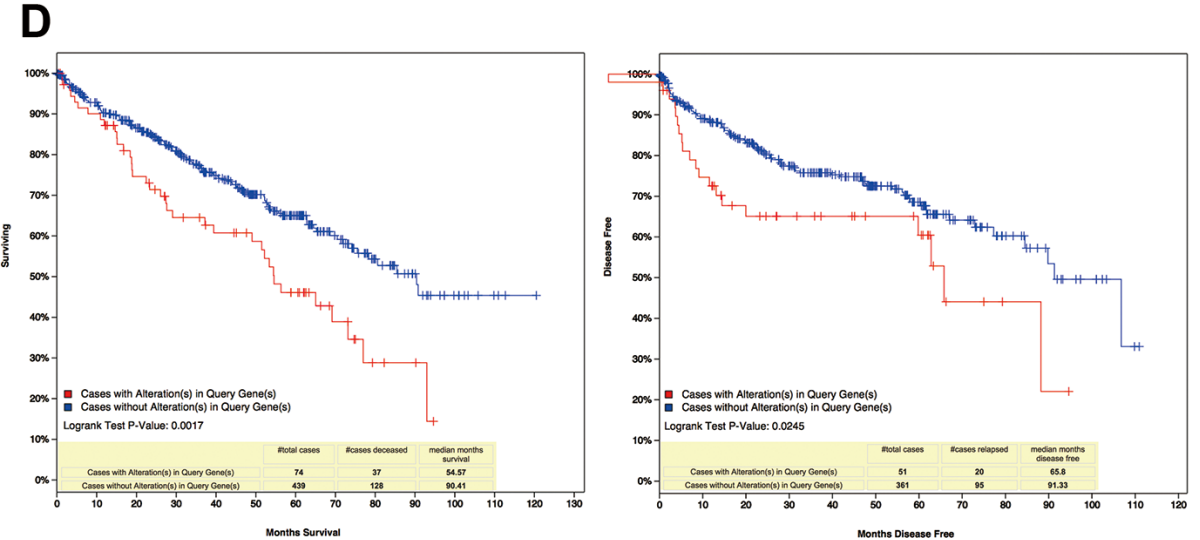

Figure 2: Association of prespecified IFN-inducible CXCR3 ligands (ICL) score with OS and RFS in non-metastatic ccRCC patients. (A) Schematic diagram for the patients with different CXCL9, CXCL10 and CXCL11 expression. (B) Kaplan-Meier analysis of OS and RFS subgrouped by prespecified ICL score. (C) Schematic diagram for the patients with different CXCL9, CXCL10 and CXCL11 expression in TCGA database (z-score threshold is 0.8). (D) Kaplan-Meier analysis of OS and RFS dichotomized by alteration of CXCL9, CXCL10 and CXCL11. 
Table 1: Associations between patient characteristics and ICL Score

\begin{tabular}{|c|c|c|c|c|c|c|}
\hline \multirow{2}{*}{ Characteristics } & \multirow{2}{*}{$\begin{array}{c}\text { Patients } \\
\text { Total (\%) }\end{array}$} & \multicolumn{5}{|c|}{ IFN-inducible CXCR3 ligands (ICL) Score } \\
\hline & & I $(n=77)$ & II $(n=64)$ & III $(n=71)$ & IV $(n=51)$ & $\boldsymbol{P}$ \\
\hline Age (years) $\dagger$ & & & & & & 0.405 \\
\hline $\begin{array}{l}\text { Mean } \\
\text { Median } \\
\text { IQR }\end{array}$ & $\begin{array}{c}56.7 \\
56 \\
48-67 \\
\end{array}$ & $\begin{array}{c}56.0 \\
54 \\
47-66 \\
\end{array}$ & $\begin{array}{c}58.7 \\
57.5 \\
51-67 \\
\end{array}$ & $\begin{array}{c}55.5 \\
54 \\
46-65 \\
\end{array}$ & $\begin{array}{c}57.1 \\
59 \\
46-68 \\
\end{array}$ & \\
\hline Gender & & & & & & 0.441 \\
\hline $\begin{array}{l}\text { Male } \\
\text { Female }\end{array}$ & $\begin{array}{c}184(70.0) \\
79(30.0)\end{array}$ & $\begin{array}{l}52 \\
25\end{array}$ & $\begin{array}{l}50 \\
14\end{array}$ & $\begin{array}{l}48 \\
23\end{array}$ & $\begin{array}{l}34 \\
17\end{array}$ & \\
\hline Tumor size $(\mathrm{cm}) \dagger$ & & & & & & 0.122 \\
\hline $\begin{array}{l}\text { Mean } \\
\text { Median } \\
\text { IQR }\end{array}$ & $\begin{array}{c}4.6 \\
4 \\
3-6\end{array}$ & $\begin{array}{c}4.2 \\
3.5 \\
2.7-5.5\end{array}$ & $\begin{array}{c}4.4 \\
4 \\
3-5.3 \\
\end{array}$ & $\begin{array}{c}4.8 \\
4 \\
3-6\end{array}$ & $\begin{array}{c}5.4 \\
5 \\
3-7 \\
\end{array}$ & \\
\hline pT stage & & & & & & 0.223 \\
\hline $\begin{array}{l}\text { pT1 } \\
\text { pT2 } \\
\text { pT3 }\end{array}$ & $\begin{array}{c}169(64.3) \\
33(12.5) \\
61(23.2) \\
\end{array}$ & $\begin{array}{l}56 \\
10 \\
11 \\
\end{array}$ & $\begin{array}{c}41 \\
7 \\
16 \\
\end{array}$ & $\begin{array}{l}45 \\
10 \\
16 \\
\end{array}$ & $\begin{array}{c}27 \\
6 \\
18 \\
\end{array}$ & \\
\hline Fuhrman grade & & & & & & $0.004 *$ \\
\hline $\begin{array}{l}1 \\
2 \\
3 \\
4\end{array}$ & $\begin{array}{c}46(17.5) \\
116(44.1) \\
67(25.5) \\
34(12.9)\end{array}$ & $\begin{array}{c}18 \\
35 \\
18 \\
6\end{array}$ & $\begin{array}{c}16 \\
33 \\
12 \\
3\end{array}$ & $\begin{array}{l}10 \\
28 \\
20 \\
13\end{array}$ & $\begin{array}{c}2 \\
20 \\
17 \\
12\end{array}$ & \\
\hline Necrosis & & & & & & $0.027 *$ \\
\hline $\begin{array}{l}\text { Absent } \\
\text { Present }\end{array}$ & $\begin{array}{c}202(76.8) \\
61(23.2) \\
\end{array}$ & $\begin{array}{l}62 \\
15 \\
\end{array}$ & $\begin{array}{l}51 \\
13 \\
\end{array}$ & $\begin{array}{l}58 \\
14 \\
\end{array}$ & $\begin{array}{l}31 \\
20\end{array}$ & \\
\hline ECOG-PS & & & & & & 0.852 \\
\hline $\begin{array}{l}0 \\
\geq 1\end{array}$ & $\begin{array}{c}226(85.9) \\
37(14.1)\end{array}$ & $\begin{array}{l}65 \\
12 \\
\end{array}$ & $\begin{array}{c}57 \\
7 \\
\end{array}$ & $\begin{array}{l}60 \\
11 \\
\end{array}$ & $\begin{array}{c}44 \\
7 \\
\end{array}$ & \\
\hline MVI & & & & & & 0.602 \\
\hline $\begin{array}{l}\text { Absent } \\
\text { Present }\end{array}$ & $\begin{array}{c}203(77.2) \\
60(22.8)\end{array}$ & $\begin{array}{l}62 \\
15\end{array}$ & $\begin{array}{l}46 \\
18\end{array}$ & $\begin{array}{l}54 \\
17\end{array}$ & $\begin{array}{l}41 \\
10\end{array}$ & \\
\hline SSIGN & & & & & & $0.001 *$ \\
\hline $\begin{array}{l}0-3 \\
4-7 \\
\geq 8\end{array}$ & $\begin{array}{c}188(71.5) \\
68(25.8) \\
7(2.7)\end{array}$ & $\begin{array}{c}64 \\
13 \\
0\end{array}$ & $\begin{array}{c}52 \\
12 \\
0\end{array}$ & $\begin{array}{c}46 \\
22 \\
3\end{array}$ & $\begin{array}{c}26 \\
21 \\
4\end{array}$ & \\
\hline
\end{tabular}

IQR, Interquartile range; MVI, Microvascular invasion; ECOG-PS, Eastern Cooperative Oncology Group performance status; SSIGN, the Mayo Clinic stage, size, grade, and necrosis score.

$\uparrow$ The results were calculated by Kruskal-Wallis test.

$* P<0.05$ is considered statistically significant.

survival and earliest recurrence (Figure 2B). Meanwhile, in C-index analysis, the value of CXCL9, CXCL10 and CXCL11 was $0.631,0.626$ and 0.598 for OS and 0.644 , 0.640 and 0.610 for RFS, respectively, and the value of ICL score improved to 0.681 for OS and 0.700 for RFS.
To further confirm the result we observed, we used TCGA database as a validation [21, 22]. In TCGA database, totally $74(14 \%)$ patients had high mRNA level of CXCL9, CXCL10 and CXCL11 (z-score threshold is 0.8) (Figure 2C). The patients with upregulation mRNA levels 
of these ligands suffered a worse survival and earlier recurrence (Figure 2D).

\section{Multivariate analysis of prespecified ICL score with OS and RFS}

To evaluate the robustness value of ICL score, multivariate Cox regression test was used to derive risk assessment correlated of OS and RFS with well-established clinicopathologic characteristics. Adjusted by these factors, prespecified ICL score remained an independent prognostic factor for OS (HR for IV vs. I $=3.84,95 \%$ $\mathrm{CI}=1.92-7.67, p<0.001)$ and RFS (HR for IV vs. $\mathrm{I}=4.66,95 \% \mathrm{CI}=1.94-11.2, p<0.001)$ (Figure 3A).

\section{Impact of prespecified ICL score on OS and RFS after adjusted by SSIGN}

At last, due to the positive relationship with SSIGN, we analyzed the impact of prespecified ICL score on OS and RFS in different subgroups of SSIGN. ICL score stratified the patients with low-risk level of SSIGN in OS (Supplementary Figure S1A) and RFS (Supplementary Figure S2B). Meanwhile, ICL score remained in the Cox model for OS (HR for IV vs. I $=3.59,95 \% \mathrm{CI}=1.79-7.20$, $p<0.001$ ) and RFS (HR for IV vs. I $=4.34,95 \%$ $\mathrm{CI}=1.80-10.5, p=0.001$ ) (Table 2). Based on the Cox analysis, the C-index of SSIGN alone was 0.705 for OS and 0.712 for RFS and improved to 0.746 for OS $(p=0.027)$ and 0.765 for RFS $(p=0.037)$ after ICL score were added (Table 2).

\section{DISCUSSION}

Involvement of CXCR3 ligands has been observed in various angiogenesis as well as immunological disorders; presumably, these ligands might provide a useful prognostic and predictive biomarker. Here, using IHC approach, we constructed a straightforward score tool based on these ligands and found ICL score stratified non-metastatic ccRCC patients into different risk subgroups.

CXCR3 ligands/CXCR3 axis represented disparate observations, due to the CXCR3 isoform, the cell type and the microenvironment where the receptor was expressed [23]. Different CXCR3 isoform had discrepant functions; CXCR3-A promoted cell proliferation and migration, while CXCR3-B inhibited cell migration and induced apoptosis [24]. In ccRCC, the CXCR3-A to CXCR3-B ratio was higher in tumor samples than in normal kidney samples, and CXCR3 expression was associated with tumor metastasis [19]. Admittedly, the detailed mechanism of CXCR3/CXCR3 ligands axis on ccRCC development was rather obscure. However, regardless of discrepant CXCR3 situation, overexpression of IFN-inducible CXCR3 ligands predicted poor clinic outcomes of ccRCC patients in TCGA and our study, suggesting a final adverse result caused by IFN-inducible CXCR3 ligands/CXCR3 axis in patients with ccRCC.

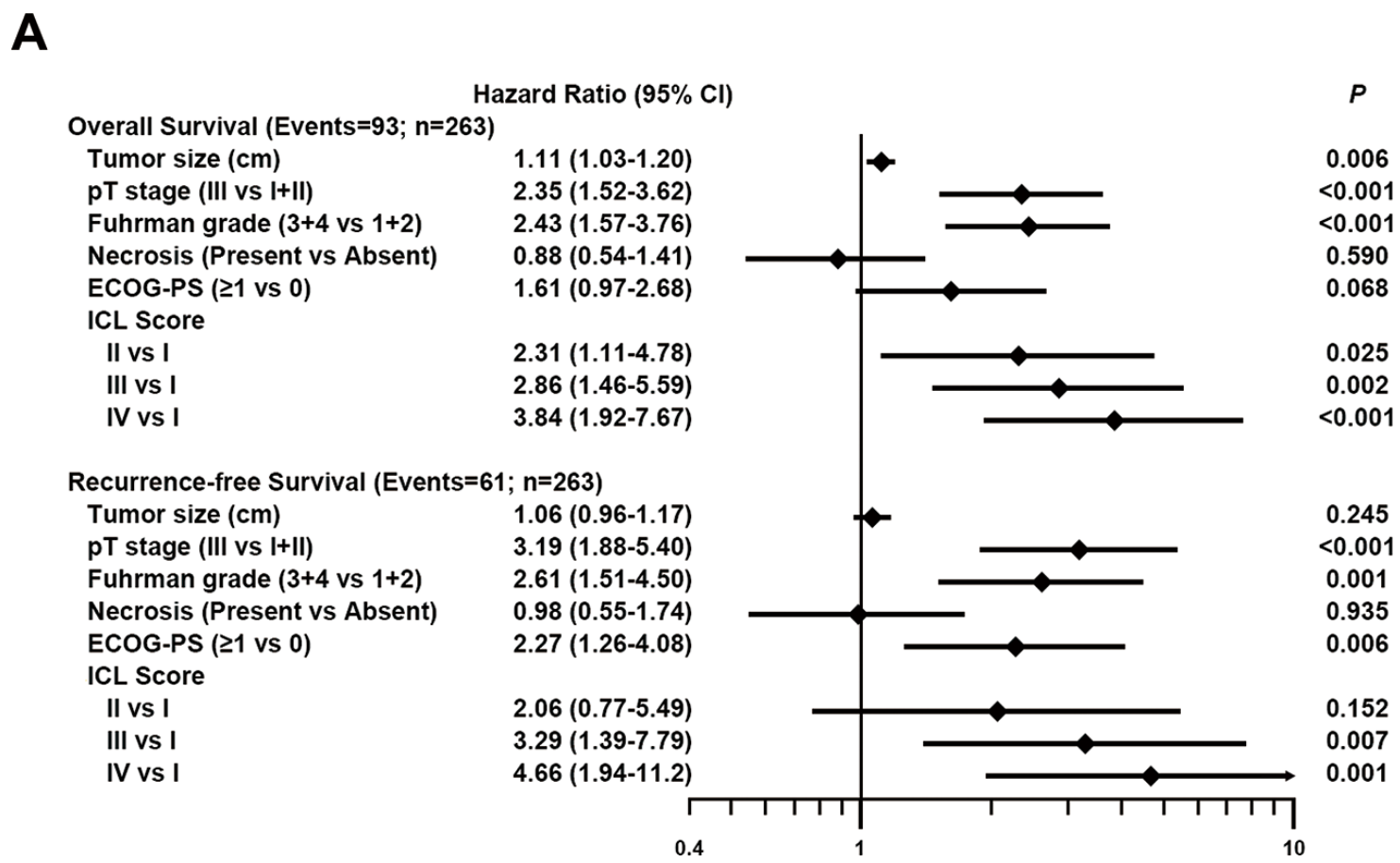

Figure 3: Multivariable Cox regression analysis associated of prespecified ICL score for OS and RFS. (A) Multivariable Cox model associated ICL score with OS and RFS after adjustment for well-established variables. 
Table 2: C-index analysis based on cox model of ICL Score and SSIGN for overall survival and recurrence-free survival of non-metastasis ccRCC patients

\begin{tabular}{|c|c|c|c|}
\hline & HR $(95 \%$ CI $)$ & $\boldsymbol{P}$ & C-index \\
\hline \multicolumn{4}{|c|}{ Overall Survival (Events $=93 ; n=263$ ) } \\
\hline SSIGN alone & $1.35(1.25-1.45)$ & $<0.001$ & 0.705 \\
\hline SSIGN +ICL Score & & & 0.746 \\
\hline SSIGN & $1.27(1.17-1.38)$ & $<0.001$ & \\
\hline II vs I & $2.14(1.04-4.38)$ & 0.040 & \\
\hline III vs I & $2.90(1.48-5.67)$ & 0.002 & \\
\hline IV vs I & $3.59(1.79-7.20)$ & $<0.001$ & \\
\hline \multicolumn{4}{|c|}{ Recurrence-free Survival (Events $=61 ; n=263$ ) } \\
\hline SSIGN alone & $1.35(1.24-1.49)$ & $<0.001$ & 0.712 \\
\hline SSIGN +ICL Score & & & 0.765 \\
\hline SSIGN & $1.27(1.15-1.40)$ & $<0.001$ & \\
\hline II vs I & $1.86(0.71-4.85)$ & 0.210 & \\
\hline III vs I & $3.23(1.37-7.63)$ & 0.008 & \\
\hline IV vs I & $4.34(1.80-10.5)$ & 0.001 & \\
\hline
\end{tabular}

ICL, IFN- $\gamma$-inducible CXCR3 ligands; HR, Hazard ratio; 95\% CI, 95\% confidence interval; SSIGN, the Mayo Clinic stage, size, grade, and necrosis score.

CXCL9, CXCL10 and CXCL11 all bound CXCR3 and elicited migration of CXCR3 expressing cells in vitro, suggesting these ligands have redundant functions; however, different regulatory elements response to different stimuli and expression on distinct cell types indicated these ligands have different temporal and spatial patterns, accounting for the unique role of them $[25,26]$. In our study, using ICL score gained a higher C-index value than using single ligand, suggesting systematic assessment of CXCL9, CXCL10 and CXCL11 status might present a more precise and comprehensive picture of functions and prognostic value of these ligands [27].

There are some limitations of our study warranting further discussion. First, given the heterogeneous nature of ccRCC and the population of our study, our conclusion might be overestimated and non-comprehensive due to these factors. Although we used TCGA database as validation, considered the different approach and cutoff methods, the further validation are warranted to confirm the stratifying function of ICL score in ccRCC patients. Second, due to small pieces of information in the original tumor using IHC approach, the readout results from patients' serum might be more convenient and reliably. Further study is necessary to determine the potential prognostic value of IFN-inducible CXCR3 ligands in serum. Third, we only focused on non-metastasis ccRCC patients. The potential prognostic value for metastatic ccRCC patients and predictive value in immune therapy need further studies to evaluate the capability of these ligands as a multifunctional biomarker for stratification and treatment for RCC patients.

\section{MATERIALS AND METHODS}

\section{Patient population}

A total of 263 non-metastatic ccRCC patients from, 2001 to 2004, who underwent radical or partial nephrectomy at Zhongshan Hospital, Shanghai, China, were enrolled in this study. The database included baseline clinicopathological characteristics and followup outcomes. The pT stage was resigned according to the American Joint Committee on Cancer 2010 TNM classification. The primary endpoint was OS with RFS as a secondary endpoint. OS and RFS were calculated from the day of surgery to the day of death and recurrence, respectively, or to the day of the last follow-up. The patients with larger necrotic and hemorrhagic area hampering the obtaining of representative area in sample or receiving preoperative neoadjuvant therapy were excluded. Ethical approval was granted by the research medical ethics committee of Fudan University. 


\section{Tissue microarray and immunohistochemistry}

Tissue microarrays were constructed as previously described [28]. Namely, formalin-fixed, paraffin-embedded tumor specimens were reviewed histologically using hematoxylin and eosin staining and two duplicate1.0-mm tissue cores from different areas were used to construct the TMA. Anti-CXCL9 CXCL10 and CXCL11 antibodies (1:100; ab9720, ab9807 and ab9955; Abcam, Cambridge, MA) were used for IHC staining. The negative controls were performed without primary antibodies. Two pathologists blinded to the clinical data evaluated the staining of each specimen. To avoid the inter-observer variability, the mean value of scores was adapted for further analysis. The staining was evaluated by semi-quantitative immunoreactivity score system, deriving from the multiplication of intensity of immunohistochemical staining ( 0 , no staining; 1 , weak; 2 , moderate and 3 , strong) and percentage of positive cells (1 point for each $10 \%$ increment; ranges from 1 to 10 ) ranges from 0 to 30 . More than medium value was considered as high expression.

\section{IFN-inducible CXCR3 ligands (ICL) score}

IFN-inducible CXCR3 ligands (ICL) score were developed based on the expression of CXCL9, CXCL10 and CXCL11 expression. The patients with no high expression of them grouped as I; with one high expression of them grouped as II; with two high expressions of them grouped as III; with all high expressions of them grouped as IV. Thus, all patients would be stratified into four prespecified risk subgroups for further analysis.

\section{Statistical analysis}

Clinicopathologic data were compared among patients stratified by ICL score, using Kruskal-Wallis and Chi-square test as appropriate. Age and tumor size were modeled as continuous variables. Meanwhile, OS and RFS were estimated by Kaplan-Meier method and analyzed by log-rank test. In addition, ICL score was further evaluated in multivariable Cox models adjusting for well-known prognostic variables and the Mayo Clinic stage, size, grade, and necrosis (SSIGN) score, respectively. C-index analysis was preformed to compare the predictive accuracy of clinical outcomes by the parameters. Statistical analysis was preformed with SPSS statistics 22. All tests were two sided and $P$ values $<0.05$ were considered statistically significant.

\section{GRANT SUPPORT}

This work was supported by grants from National Basic Research Program of China (2012CB822104), National Natural Science Foundation of China (31100629,
31270863, 31300671, 81372755, 31470794, 81401988, $81402082,81402085,81471621,81472227,81472376$, 31570803 and 81572352), Program for New Century Excellent Talents in University (NCET-13-0146), and Shanghai Rising-Star Program (13QA1400300). All these study sponsors have no roles in the study design, in the collection, analysis, and interpretation of data.

\section{CONFLICTS OF INTEREST}

The authors declare no conflicts of interest.

\section{REFERENCES}

1. Yang JC, Childs R. Immunotherapy for renal cell cancer. J Clin Oncol. 2006; 24:5576-5583.

2. Song W, Yeh CR, He D, Wang Y, Xie H, Pang ST, Chang LS, Li L, Yeh S. Infiltrating neutrophils promote renal cell carcinoma progression via $\mathrm{VEGFa} / \mathrm{HIF} 2$ alpha and estrogen receptor beta signals. Oncotarget. 2015. doi: 10.18632/oncotarget.4478.

3. Gustafson MP, Lin Y, Bleeker JS, Warad D, Tollefson MK, Crispen PL, Bulur PA, Harrington SM, Laborde RR, Gastineau DA, Leibovich BC, Cheville JC, Kwon ED. Intratumoral CD14+ Cells and Circulating CD14+HLADRlo/neg Monocytes Correlate with Decreased Survival in Patients with Clear Cell Renal Cell Carcinoma. Clin Cancer Res. 2015; 107.

4. Giraldo NA, Becht E, Pages F, Skliris G, Verkarre V, Vano Y, Mejean A, Saint-Aubert N, Lacroix L, Natario I, Lupo A, Alifano M, Damotte D, et al. Orchestration and Prognostic Significance of Immune Checkpoints in the Microenvironment of Primary and Metastatic Renal Cell Cancer. Clin Cancer Res. 2015; 21:3031-3040.

5. Moser B, Loetscher P. Lymphocyte traffic control by chemokines. Nat Immunol. 2001; 2:123-128.

6. Hanahan D, Folkman J. Patterns and emerging mechanisms of the angiogenic switch during tumorigenesis. Cell. 1996; 86:353-364.

7. Van Raemdonck K, Van den Steen PE, Liekens S, Van Damme J, Struyf S. CXCR3 ligands in disease and therapy. Cytokine Growth Factor Rev. 2015; 26:311-327.

8. Shiels MS, Katki HA, Hildesheim A, Pfeiffer RM, Engels EA, Williams M, Kemp TJ, Caporaso NE, Pinto LA, Chaturvedi AK. Circulating Inflammation Markers, Risk of Lung Cancer, and Utility for Risk Stratification. J Natl Cancer Inst. 2015; 107.

9. Datta D, Flaxenburg JA, Laxmanan S, Geehan C, Grimm M, Waaga-Gasser AM, Briscoe DM, Pal S. Ras-induced modulation of CXCL10 and its receptor splice variant CXCR3-B in MDA-MB-435 and MCF-7 cells: relevance for the development of human breast cancer. Cancer Res. 2006; 66:9509-9518.

10. Mulligan AM, Raitman I, Feeley L, Pinnaduwage D, Nguyen LT, O’Malley FP, Ohashi PS, Andrulis IL. Tumoral 
lymphocytic infiltration and expression of the chemokine CXCL10 in breast cancers from the Ontario Familial Breast Cancer Registry. Clin Cancer Res. 2013; 19:336-346.

11. Suyama T, Furuya M, Nishiyama M, Kasuya Y, Kimura S, Ichikawa $\mathrm{T}$, Ueda $\mathrm{T}$, Nikaido $\mathrm{T}$, Ito $\mathrm{H}$, Ishikura H. Upregulation of the interferon gamma (IFN-gamma)-inducible chemokines IFN-inducible T-cell alpha chemoattractant and monokine induced by IFN-gamma and of their receptor CXC receptor 3 in human renal cell carcinoma. Cancer. 2005; 103:258-267.

12. Kondo T, Ito F, Nakazawa H, Horita S, Osaka Y, Toma H. High expression of chemokine gene as a favorable prognostic factor in renal cell carcinoma. J Urol. 2004; 171:2171-2175.

13. Pan J, Burdick MD, Belperio JA, Xue YY, Gerard C, Sharma S, Dubinett SM, Strieter RM. CXCR3/ CXCR3 ligand biological axis impairs RENCA tumor growth by a mechanism of immunoangiostasis. J Immunol. 2006; 176:1456-1464.

14. Reckamp KL, Figlin RA, Moldawer N, Pantuck AJ, Belldegrun AS, Burdick MD, Strieter RM. Expression of CXCR3 on mononuclear cells and CXCR3 ligands in patients with metastatic renal cell carcinoma in response to systemic IL-2 therapy. J Immunol. 2007; 30:417-424.

15. Oldham KA, Parsonage G, Bhatt RI, Wallace DM, Deshmukh N, Chaudhri S, Adams DH, Lee SP. T lymphocyte recruitment into renal cell carcinoma tissue: a role for chemokine receptors CXCR3, CXCR6, CCR5, and CCR6. Eur Urol. 2012; 61:385-394.

16. Liotta F, Gacci M, Frosali F, Querci V, Vittori G, Lapini A, Santarlasci V, Serni S, Cosmi L, Maggi L, Angeli R, Mazzinghi B, Romagnani P, et al. Frequency of regulatory $\mathrm{T}$ cells in peripheral blood and in tumour-infiltrating lymphocytes correlates with poor prognosis in renal cell carcinoma. BJU Int. 2011; 107:1500-1506.

17. Griffiths RW, Elkord E, Gilham DE, Ramani V, Clarke N, Stern PL, Hawkins RE. Frequency of regulatory $T$ cells in renal cell carcinoma patients and investigation of correlation with survival. Cancer Immunol Immunother. 2007; 56:1743-1753.

18. Jensen HK, Donskov F, Nordsmark M, Marcussen N, von der Maase H. Increased intratumoral FOXP3-positive regulatory immune cells during interleukin-2 treatment in metastatic renal cell carcinoma. Clin Cancer Res. 2009; 15:1052-1058.
19. Utsumi T, Suyama T, Imamura Y, Fuse M, Sakamoto S, Nihei N, Ueda T, Suzuki H, Seki N, Ichikawa T. The association of CXCR3 and renal cell carcinoma metastasis. J Urol. 2014; 192:567-574.

20. Ierano C, Santagata S, Napolitano M, Guardia F, Grimaldi A, Antignani E, Botti G, Consales C, Riccio A, Nanayakkara M, Barone MV, Caraglia M, Scala S. CXCR4 and CXCR7 transduce through mTOR in human renal cancer cells. Cell Death Dis. 2014; 5:e1310.

21. Cerami E, Gao J, DogrusozU, Gross BE, Sumer SO, Aksoy BA, Jacobsen A, Byrne CJ, Heuer ML, Larsson E, Antipin Y, Reva B, Goldberg AP, et al. The cBio cancer genomics portal: an open platform for exploring multidimensional cancer genomics data. Cancer Discov. 2012; 2:401-404.

22. Gao J, Aksoy BA, Dogrusoz U, Dresdner G, Gross B, Sumer SO, Sun Y, Jacobsen A, Sinha R, Larsson E, Cerami E, Sander C, Schultz N. Integrative analysis of complex cancer genomics and clinical profiles using the cBioPortal. Sci Signal. 2013; 6:pl1.

23. Billottet C, Quemener C, Bikfalvi A. CXCR3, a doubleedged sword in tumor progression and angiogenesis. Biochim Biophys Acta. 2013; 1836:287-295.

24. Lasagni L, Francalanci M, Annunziato F, Lazzeri E, Giannini S, Cosmi L, Sagrinati C, Mazzinghi B, Orlando C, Maggi E, Marra F, Romagnani S, Serio M, et al. An alternatively spliced variant of CXCR3 mediates the inhibition of endothelial cell growth induced by IP-10, Mig, and I-TAC, and acts as functional receptor for platelet factor 4. J Exp Med. 2003; 197:1537-1549.

25. Medoff BD, Wain JC, Seung E, Jackobek R, Means TK, Ginns LC, Farber JM, Luster AD. CXCR3 and its ligands in a murine model of obliterative bronchiolitis: regulation and function. J Immunol. 2006; 176:7087-7095.

26. Campanella GS, Tager AM, El Khoury JK, Thomas SY, Abrazinski TA, Manice LA, Colvin RA, Luster AD. Chemokine receptor CXCR3 and its ligands CXCL9 and CXCL10 are required for the development of murine cerebral malaria. Proc Natl Acad Sci U S A. 2008; 105:4814-4819.

27. Groom JR, Luster AD. CXCR3 ligands: redundant, collaborative and antagonistic functions. Immunol Cell Biol. 2011; 89:207-215.

28. Xu L, Zhu Y, Chen L, An H, Zhang W, Wang G, Lin Z, $\mathrm{Xu}$ J. Prognostic value of diametrically polarized tumorassociated macrophages in renal cell carcinoma. Ann Surg Oncol. 2014; 21:3142-3150. 